\title{
Discussão dos Conceitos de Massa Inercial e Massa Gravitacional
}

Discussion on the concepts of inertial mass and gravitational mass

\author{
Otávio Cesar Castellani \\ Departamento de Campos e Partículas \\ Centro Brasileiro de Pesquisas Físicas \\ Rua Dr. Xavier Sigaud, 150, 22290-180, Rio de Janeiro, RJ \\ otavio@cbpf.br
}

Recebido em 27 de Julho 2001. Aceito em 3 de Setembro 2001

\begin{abstract}
Por mais de dois séculos a igualdade entre massa inercial e massa gravitacional foi um mistério na Física. Até que no início do século XX nasceu uma teoria que explicasse essa igualdade. Neste trabalho discutimos os conceitos referentes a essas massas bem como a origem da teoria da Relatividade Geral, que tem como base justamente a igualdade entre elas. O texto a seguir serve também como objeto de discussão para alunos de ensino médio e de ensino superior, pois fornece uma compreensão mais sólida dos conceitos envolvidos.
\end{abstract}

For more than two centuries, the equality between inertial mass and gravitational mass has been a mistery in Physics, until early in the XX century a theory that could explain such equality appeared. In the present work we discuss the concepts concerning those masses, as well as the origin of the theory of General Relativity, which relies in their very equality. The following text is also suitable as a discussion item for high-school and undergraduate students, providing a more solid understanding of the concepts involved.

\section{Introdução}

A Mecânica, parte da Física que estuda o movimento e suas causas, está fundamentada em três leis que conhecemos como as 3 Leis de Newton, por ele publicadas em 1687 no Princípios Matemáticos da Filosofia Natural, mais conhecido como Principia. Nestes livro ${ }^{1}$, Isaac Newton expõe todas as suas conclusões a respeito do movimento e principalmente da gravidade. Em nossas escolas de ensino médio, e até no ensino superior, estas leis, muitas vezes, são ensinadas de maneira mecânica (não confundir com a área da Física), fazendo com que o aluno não compreenda o verdadeiro significado destas leis. A $2 \underline{a}$ Lei de Newton, conhecida como Lei Fundamental da Dinâmica, se reduz no ensino médio a $\vec{F}=m \vec{a}$ e no ensino superior a $\vec{F}=\frac{d \vec{p}}{d t}$, sem nenhuma discussão profunda das grandezas envolvidas na equação. Para o aluno, a $2 \underline{a}$ Lei expressa apenas uma lei que define força.

Este trabalho é dirigido a professores de ensino médio (ou superior) que desejam enriquecer suas au- las com questões conceituais de grande importância no ensino de Física, para que não deixe sua aula reduzida simplesmente em três letras, $F, m$ e $a$.

\section{Anos Maravilhosos}

Durante os "Anos Maravilhosos", 1665-1666, Isaac Newton constrói toda uma teoria baseada na observação e na sua grande capacidade intuitiva. Nessa época, a visão dos filósofos sobre espaço e tempo estava muito ligada à divindade e muitos fenômenos físicos eram tomados como sendo governados por Deus. Mesmo Newton, de certa forma, está preso à sua própria religiosidade e muito da sua visão sobre a natureza demonstra uma submissão ao desejo divino ${ }^{2}$. A definição de espaço absoluto, de que ele permanece sempre imutável e imóvel deve-se possivelmente à sua visão de Deus, como podemos perceber em uma passagem do livro III do Principia[1], Do Sistema do Mundo:

\footnotetext{
${ }^{1}$ O Principia é composto de 3 volumes. No primeiro e no segundo volumes são apresentadas as definições, leis e o estudo do movimento dos corpos e no terceiro, Do Sistema do Mundo, é apresentado toda a base para a gravitação universal.

${ }^{2}$ Entre outras coisas, a não aceitação por ele da teoria dos vórtices de Descartes[1,3] deve-se ao fato de que tal teoria considera a ação da Divindade apenas no início do Universo, sendo a presença de Deus portanto, totalmente descartável para os fenômenos do dia-a-dia.
} 
"Esse Ser governa todas as coisas, não como a alma do mundo, mas como Senhor de tudo; e por causa de seu domínio costumase chamá-lo Senhor Deus Pantokrátor, ou Soberano Universal; pois Deus é uma palavra relativa e tem uma referência a servidores...Ele é eterno e infinito, onipotente e onisciente; isto é, sua duração se estende da eternidade à eternidade; sua presença do infinito ao infinito; ele governa todas as coisas e conhece todas as coisas que são ou podem ser feitas."

Mesmo preso à sua religiosidade, ele consegue mostrar o que todos em sua época não aceitavam, que a Física dos céus é a mesma Física da Terra.

No Principia, a grandeza que representa a quantidade de matéria contida num corpo, que chamamos de massa, possui naturezas diferentes quando aplicamos a $2 \stackrel{a}{a}$ lei de Newton ao campo gravitacional. A igualdade entre a massa inercial e gravitacional foi um mistério na física Newtoniana, sendo apenas aceita por ser fato experimental. Mas em nenhum momento essa igualdade é explicada. Nas seções seguintes tentaremos fazer uma análise dessa questão, mostrando finalmente a elucidação desse fato realizado no início do século XX.

\section{O princípio fundamental da dinâmica: Massa inercial}

No livro I, Newton apresenta suas 3 leis do movimento, onde a $2 \underline{a}$ lei é conhecida como lei fundamental da dinâmica:

"A mudança do movimento é proporcional à força motriz impressa, e se faz segundo a linha reta pela qual se imprime essa força."

A leitura mais comum dessa lei pode ser expressa por uma equação ${ }^{3}$ dada por:

$$
F=\frac{\Delta p}{\Delta t}
$$

em que $p=m v$ é a quantidade de movimento, que também foi definida por Newton em seu Principia. Se a massa do corpo não variar com o tempo a Eq. (1) pode ser escrita como ${ }^{4}$

$$
F=m \frac{\Delta v}{\Delta t}=m a,
$$

com $a$ sendo a aceleração adquirida pelo corpo e $m$ a sua massa. Nesse momento $m$ é apresentada simplesmente como a massa do corpo e a sua verdadeira natureza é omitida.

Para encontrarmos uma expressão para o peso de um corpo, além de fazermos uma analogia com a Eq. (2), buscamos também na experiência, que a aceleração de um corpo em queda livre é igual à aceleração da gravidade $g$, e então escrevemos ${ }^{5}$

$$
W=m g
$$

sendo $W$ o peso do corpo. Mas será que essa analogia com a Eq. (2) é óbvia? As massas nas Eqs. (2) e (3) são conceitualmente iguais?

Na Definição I do primeiro volume do Principia, Newton escreve[1]:

"A quantidade de matéria é a medida da mesma, oriunda conjuntamente da sua densidade e grandeza"

Logo depois, na Definição III, o conceito dessa massa fica mais claro, pois ele fala justamente da sua propriedade de resistência ao movimento ${ }^{6}$;

"A força inata (ínsita) da matéria é um poder de resistir pelo qual cada corpo, enquanto depende dele, persevera em seu estado, seja de descanso, seja de movimento uniforme em linha reta."

Tecendo em seguida os seguintes comentários:

"Essa força é sempre proporcional ao seu corpo, e não difere da inércia da massa senão no nosso modo de conceber. É pela inércia da matéria que todo corpo dificilmente sai de seu estado de descanso ou de movimento...Mas um corpo só exerce essa força quando da mutação de seu estado por outra força impressa em si; e o exercício dessa força pode ser considerado sob duplo aspecto de resistência e de ímpeto: resistência, enquanto, para conservar o seu estado, o corpo se opõe à força impressa; ímpeto, enquanto o mesmo corpo, dificilmente cedendo à força do obstáculo oposto, esforça-se por mudar o estado deste..."

Continuando então, com a Definição IV:

"A ação impressa é uma ação exercida sobre um corpo para mudar seu estado de repouso ou de movimento uniforme em linha reta."

\footnotetext{
${ }^{3}$ Ao contrário do que muitos pensam, essa equação não aparece no Principia. Ela foi escrita anos mais tarde por outros filósofos.

${ }^{4} \mathrm{~A} 2 \underline{a}$ lei nessa forma foi apresentada pela primeira vez em 1747 por Euler em " Recherches sur le mouvement des corps célestes en général " e em 1749 foi publicada nas Mémoires de L'Académie des Sciences de Berlin.

${ }^{5}$ A definição de peso como o produto da massa pela aceleração da gravidade apareceu com o trabalho de Jean Bernoulli, em 1742 .

${ }^{6}$ Newton ainda se mostra preso à física antiga, pois admite que a inércia seja uma força que seria propriedade do corpo.
} 
Comentando então:

"Esta força consiste somente na ação, nem permanece no corpo depois dela. De fato, um corpo persevera em todo novo estado, apenas pela força de inércia ${ }^{7}$..."

Logo, uma leitura mais exata da $2 \stackrel{a}{a}$ lei nos mostra a verdadeira natureza dessa massa. Quando Newton usa o termo força motriz, ele se refere a uma força (ação) que atua em um intervalo de tempo pequeno (Definição IV), ou seja, somente para alterar o estado do corpo. Logo, matematicamente a $2^{a}$ lei é escrita $\operatorname{como}^{8}$ :

$$
F \Delta t=\Delta p=m \Delta v
$$

$\mathrm{Na}$ verdade a massa $m$ da $2 \underline{a}$ lei mede a tendência que o corpo tem para conservar o seu movimento "natural" (retilíneo e uniforme), o que está de acordo com nossa intuição de que quanto mais massivo for o corpo, mais difícil será tirá-lo do repouso, fazê-lo parar ou mudar sua direção de movimento. Por isso, o nome dado de massa inercial.

\section{Massa gravitacional}

Durante algum tempo os pontos relacionados à gravidade estavam obscuros para Newton. Podemos perceber que não é óbvia a analogia entre (2) e (3), pois o peso é uma força que atua em um intervalo de tempo muito grande, ou seja, o peso está sempre atuando no corpo e a $2 \underline{a}$ lei não se refere a este tipo de força. Mas como resolver este problema se o peso é uma força?

O peso é uma força que também depende da massa do corpo, mas nesse caso, a massa não aparece como uma característica do corpo de preservar o seu "movimento natural", já que um corpo submetido à força peso sempre entrará em movimento (queda livre). Ela aparece como uma reação do corpo à ação gravitacional. A essa massa foi dada o nome de massa gravitacional.

Desde a publicação, em 1638, de Duas Novas Ciências $^{9}$ de Galileu Galilei, o diálogo entre Salviati (personagem que fala por Galileu), Sagredo (homem com mente aberta e inteligente) e Simplício (o aristotélico) destrói toda uma base aristotélica de pensamento, de que um corpo mais pesado cairia mais rápido que um corpo mais leve. É fato experimental que, independente de suas massas, dois corpos adquirem a mesma velocidade ao chegarem ao solo, quando abandonados da mesma altura. Fato este discutido na primeira jornada de Duas Novas Ciências[2]. Logo, para um corpo em queda livre devemos ter

$$
a=g \text {. }
$$

Mas ao analisarmos a queda (considerada no vácuo), verificamos que a única força atuante no corpo foi o peso, com isso:

$$
\begin{gathered}
W=F \\
m_{g} g=m_{i} a,
\end{gathered}
$$

e para (1) ser verdade devemos ter $m_{i}=m_{g}$. Na mecânica newtoniana essa igualdade é simplesmente uma coincidência, não havendo nenhuma explicação para esse fato. A natureza nos mostra que existe essa igualdade, pois se isso não fosse verdade, dois corpos abandonados da mesma altura chegariam ao solo em tempos diferentes, logo com velocidades diferentes.

\section{O pensamento mais feliz...}

Em 1907, durante a preparação de um artigo sobre a teoria da relatividade restrita, Abert Einstein perguntou a si mesmo de que modo a Teoria da Gravitação de Newton deveria ser modificada para que suas leis se ajustassem à Relatividade Restrita. Nessa época ele teve o que chamou de "glücklichste gedanke meines lebens" (pensamento mais feliz da minha vida). Suas conclusões foram relatadas anos mais tarde[4]:

"Esta lei...da igualdade da massa inercial e
da massa gravitacional foi então percebida
por mim com todo o seu significado. Fi-
quei abismado com sua existência e conje-
turei que ela deveria conter a chave para
uma compreensão mais profunda da inércia
e da gravitação."

Em 1916, Einstein publica sua teoria da gravitação (Teoria da Relatividade Geral) e uma das bases da sua teoria é justamente a igualdade da massa inercial e da massa gravitacional, que está nas entrelinhas do Princípio da Equivalência[4] :

Num pequeno laboratório em queda livre num campo gravitacional, as leis físicas são as mesmas que num referencial inercial na ausência do campo gravitacional.

Vamos entender melhor estas palavras usando o exemplo que o próprio Einstein usou. O chamado "elevador de Einstein":

\footnotetext{
${ }^{7} \mathrm{O}$ que Newton chama de Força de Inércia é a " força de resistência ao movimento ", que todo o corpo possui. Não deve-se confundir com Forças Fictícias, que aparecem em referenciais acelerados.

${ }^{8} \mathrm{O}$ enunciado da $2 \stackrel{a}{a}$ Lei, matematicamente, é o que hoje chamamos de Impulso.

${ }^{9}$ Em Duas Novas Ciências, Galileu nos descreve um diálogo entre três personagens que discutem situações que derrubam a Física aristotélica. Esse diálogo ocorre em quatro jornadas, onde são discutidos resistência dos corpos sólidos, movimento uniforme e acelerado e movimento de projéteis.
} 
Imagine um homem no interior de um elevador sem ter conhecimento algum do que ocorre no exterior. Leve este elevador para o espaço sideral longe de qualquer campo gravitacional. O homem ficará flutuando no interior do elevador, pois não há a atuação da força peso. Se ele soltar uma bola, ela permanecerá no mesmo lugar em que foi solta, pois do mesmo modo não há força gravitacional atuando. Agora deixe esse elevador em queda livre num campo gravitacional. $\mathrm{O}$ homem e o elevador irão cair juntos. As paredes do elevador não se movem em relação ao homem, dando-lhe a impressão de que ele está flutuando. Se ele soltar uma bola, esta continuará na mesma posição em relação ao homem (pois cai junto com ele). Ou seja, para o homem os experimentos que ele fizer se comportarão da mesma maneira nas duas situações.

Outra versão do Princípio da Equivalência pode ser escrita como se segue[5]:

Um referencial acelerado é idêntico a um referencial em repouso em um campo gravitacional.

Para entender esta nova forma vamos voltar ao exemplo do elevador:

Imagine o mesmo homem no mesmo elevador na superfície de um planeta. O homem deixa cair uma bola no interior do elevador e verifica que ela cai com aceleração da gravidade $g$. O próprio homem sente a ação do campo, pois seu corpo pressiona o chão do elevador. Agora leve este elevador para o espaço sideral, longe de qualquer ação gravitacional (lembre-se que estamos considerando que o homem não percebe nada). Acelere o elevador para cima com uma aceleração $g$. Tal aceleração será transmitida para o homem em sentido oposto. $\mathrm{O}$ homem solta uma bola e verifica que esta atinge o chão do elevador com aceleração $g$. Ele mesmo sente seus pés pressionarem o chão do elevador. Logo, tudo se passa como se ele estivesse em um campo gravitacional, ou seja, o homem não consegue distinguir um referencial acelerado de um referencial imerso num campo gravitacional.

Ou seja, gravitação e inércia são duas palavras para uma mesma coisa. A natureza da massa dependerá do ponto de vista do observador, daí vem a igualdade da massa gravitacional e da massa inercial. Considere a segunda experiência do elevador, quando este se encontra no espaço sideral acelerado para cima com aceleração $g$.
Ao soltar a bola ele verifica que esta atinge o chão com aceleração $g$, ele portanto, pode concluir que está num campo gravitacional e que a força peso da bola atuou fazendo com que ela entrasse em movimento. Logo, para ele a massa da bola será a massa gravitacional. Mas se um observador externo observar o movimento do elevador, verificará que a aceleração $g$ da bola é devido a aceleração adquirida pelo elevador quando submetido à ação de uma força $F$. Então, para o observador externo a massa da bola, nada mais é, do que a massa inercial.

Mas qual dos dois observadores estará correto?

$\mathrm{Na}$ verdade os dois estão corretos. A descrição do Universo não dependerá do ponto de vista do observador. As leis físicas devem ser as mesmas em qualquer referencial sem que haja um referencial privilegiado.

\section{Conclusões}

Como podemos ver, a igualdade entre massa inercial e massa gravitacional esperou por mais de 200 anos para que uma teoria pudesse explicá-la. Foi preciso um grande poder de abstração e intuição, para reconhecer filosoficamente a explicação para essa lei.

Vejo que é de grande importância a apresentação de questões filosóficas no ensino de Física, seja no ensino médio ou no ensino superior, pois deixa transparente para os alunos que a Física não é a verdade absoluta (como muitas vezes é apresentada). Ela é uma descrição limitada devido à própria limitação do ser humano.

\section{References}

[1] Newton-Leibniz, Princípios Matemáticos da Filosofia Natural, Os Pensadores, Editora Victor Civita, 1983. O Peso e o equilíbrio dos Fluidos, Os Pensadores, Editora Victor Civita, 1983, p. 59-90.

[2] Galileu Galilei, Duas Novas Ciências, Editora Nova Stella, 1988.

[3] Mario Barbatti, A Filosofia Natural à Época de Newton, Rev. Bras. Ens. Fis. 21, no. 1, 153 (1999).

[4] H. Moysés Nussenzveig, Curso de Física Básica vol. 1, Clarendon Press, Oxford, 1988.

[5] Ray D'Inverno, Introducing Einstein's Relativity, Edgard Blücher Ltda,1992.

[6] Voltaire, Elementos da Filosofia de Newton, Editora da UNICAMP, 1996.

[7] Vittorio Silvestrini, Introdução à Teoria da Relatividade, Editorial Notícias.

[8] Silvio Seno Chibeni, A Fundamentação Empírica das Leis Dinâmicas de Newton, Rev. Bras. Ens. Fis. 21, no. 1, 1 (1999).

[9] José Plínio Baptista e Laércio Ferracioli, A Construção de Princípio de Inércia e do Conceito de Inércia Material, Rev. Bras. Ens. Fis. 22, no. 2, 272 (2000). 